\title{
A spectroscopic study to assess the photogeneration of singlet oxygen by graphene oxide
}

\author{
Carles Felip-León ${ }^{\mathrm{a}}$, Marta Puche ${ }^{\mathrm{b}}$, Juan F. Miravet ${ }^{\mathrm{a}}$, Francisco Galindo ${ }^{\mathrm{a}}$ *, Marta Feliz ${ }^{\mathrm{b}}$ * \\ ${ }^{a}$ Universitat Jaume I, Departamento de Química Inorgánica y Orgánica, Avda. Sos Baynat s/n, 12071 Castellón, Spain \\ ${ }^{\mathrm{b}}$ Instituto de Tecnología Química (Universitat Politècnica de València - Consejo Superior de Investigaciones Científicas), Avd de los Naranjos s/n, 46022 Valencia, Spain
}

\section{A R T I C L E I N F O}

\section{Keywords:}

Singlet oxygen

Reactive oxygen species

Graphene oxide

Fluorescent probe

\begin{abstract}
A B S T R A C T
The photogeneration of singlet oxygen $\left({ }^{1} \mathrm{O}_{2}\right)$ during short irradiation times of graphene oxide (GO) is assessed under visible light with soft irradiation conditions either directly monitoring the phosphorescence emission of ${ }^{1} \mathrm{O}_{2}$ at $c a .1275 \mathrm{~nm}$, or indirectly by means of the fluorescent probe 9,10-anthracenediyl-bis(methylene)dimalonic acid (ABDA). Results obtained using both methodologies lead to the conclusion that ${ }^{1} \mathrm{O}_{2}$ generation is negligible under our experimental conditions. In the case of using ABDA very small emission changes were recorded, which could be attributed to other side reactions. Special care should be taken when using this spectroscopic probe to assess the generation of ${ }^{1} \mathrm{O}_{2}$, since ABDA and related probes based on the reactivity of the anthracene fluorophore can also detect electron transfer processes. This kind of approaches have been less explored in the field of Materials Science at the nanoscale, and we believe that the knowledge on the lack of generation of ${ }^{1} \mathrm{O}_{2}$ by irradiated GO is informative and useful, especially for the assessment of the environmental and biological toxicity of nanomaterials based on GO.
\end{abstract}

\section{Introduction}

Carbon based nanomaterials are gaining increasing attention taking into account their outstanding physical properties. Numerous applications have been found in the fields of electronics, energy storage and biomedical areas, to mention only a few. The interest in this family of materials is expected to grow exponentially in the coming years [1-15]. Despite the efforts devoted to understand the chemistry of graphene and its derivatives still important questions remain to be answered. Some of those questions are concerns about their potential environmental toxicity [16-25], and to the in vivo toxicity of graphene, GO and derived hybrid nanocomposites used for biological imaging and therapy $[15,26,27,28,29]$. In this last realm, the use of short exposure times to light (minutes) is frequent, in contrast to environmental studies (hours). Reactive oxygen species (ROS) such as singlet oxygen $\left({ }^{1} \mathrm{O}_{2}\right)$, superoxide radical anion $\left(\mathrm{O}_{2}{ }^{-*}\right)$ and hydroxyl radical $\left({ }^{\bullet} \mathrm{OH}\right)$ have been detected upon irradiation of fullerenes [30], carbon nanotubes [31,32], and graphene quantum dots [33]. However, the investigation of ROS production by GO and reduced graphene oxide (rGO) is much recent. Krishnamoorthy et al. reported on the behaviour of GO as a photoreductant but not informed about the generation of ROS [34].

\footnotetext{
* Corresponding authors.

Email addresses: francisco.galindo@uji.es (F. Galindo); mfeliz@itq.upv.es (M. Feliz)
}

More recently the group of Jafvert detected $\mathrm{O}_{2}-^{-}$but not ${ }^{1} \mathrm{O}_{2}$ or ${ }^{\bullet} \mathrm{OH}$ after irradiation of GO in water [35]. Later, the group of Sarkar reported that $\mathrm{rGO}$ was responsible for the production of ROS in aged samples of $\mathrm{GO}$ (suggesting the involvement of ${ }^{1} \mathrm{O}_{2}$, although not directly detected) [36]. More recently, Li, Keller et al. have studied the photochemistry GO and $\mathrm{rGO}$, finding that $\mathrm{O}_{2}{ }^{-}$was the most abundant ROS generated upon irradiation during long irradiation times $(>24 \mathrm{~h})$ using high-power light sources (800 W Xe lamp) $[37,38]$. In this case, the concentration of ${ }^{1} \mathrm{O}_{2}$ was found $<3 \cdot 10^{-14} \mathrm{M}$.

The most frequently used probe for determining the ${ }^{1} \mathrm{O}_{2}$ production is FFA [39]. But the use of this molecule requires a centrifugation step and HPLC analysis for monitoring the reaction. In the last years, very sensitive spectroscopic probes based on fluorescence are gaining acceptance since they allow an in situ measurement of the reaction progress, especially for short irradiation times. In the course of our research on graphene composites [40], we were interested in the analysis of ROS produced by GO, and we hypothesized that highly-sensitive spectroscopic methods to detect ${ }^{1} \mathrm{O}_{2}$ could be used as a complement to chromatographic ones. Hence we turned our attention to fluorescent probes based on anthracene as ${ }^{1} \mathrm{O}_{2}$ indicators. Additionally, we combined this approach with the direct measurement of ${ }^{1} \mathrm{O}_{2}$ phosphorescence at $c a$. 
$1275 \mathrm{~nm}$. Our investigation confirms that ${ }^{1} \mathrm{O}_{2}$ production upon irradiation of GO is minimal, as reported with the traditional FFA method $[35,37]$. This finding is applicable specifically to the sample of GO prepared by us; samples with a different degree of oxidation or aging after preparation could have a different behaviour. This fact highlights the utility of having a variety of detection methods to assess the production of ROS in graphene derived materials. The need of a toolbox of probes for ROS is strongly recommended in GO research, especially to evaluate the interaction of GO based nanomaterials with biological media $[41,42]$.

\section{Materials and methods}

\subsection{Chemicals}

Graphite (powder $<20 \mu \mathrm{m}$, synthetic), potassium permanganate, sulfuric acid, phosphoric acid, ABDA, 9,10-dimethylanthracene (DMA), Rose Bengal (RB), sodium azide, and fullerene- $\mathrm{C}_{60}$ have been obtained from commercial resources, and used as received.

\subsection{Instrumentation}

Combustion chemical analysis of the samples were carried out using a Fisons EA 1108-CHNS-O analyzer. Fourier-transform infrared spectroscopy (FT-IR) spectra were measured on $\mathrm{KBr}$ pellets with a Nicolet 8700 Thermo spectrometer. The Raman spectra were obtained from solid samples previously deposited onto aluminium or quartz wafers, indistinctively, using a "Reflex" Renishaw spectrometer, equipped with an Olympus microscope. The exciting wavelength was $514 \mathrm{~nm}$ of an $\mathrm{Ar}^{+}$ion laser. The laser power on the sample was $\sim 10-25 \mathrm{~mW}$ and a total of 20 acquisitions were taken for each spectra. UV-Vis spectra were recorded in solution on JASCO V-630 spectrophotometer. Fluorescence measurements were recorded using a JASCO FP-8300 apparatus. Solid-state ${ }^{13} \mathrm{C}$ imagic angle spinning nuclear magnetic resonance (MAS-NMR) spectra were recorded at RT by using a Bruker AV400WB spectrometer. The samples were spinning at the magic angle at $10 \mathrm{kHz}$, choosing $\mu / 2$ pulses of $5 \mu$ s and a recycle delay of $5 \mathrm{~s}$. Powder X-ray diffraction (XRD) patterns were obtained by using a Philips $\mathrm{X}$ 'Pert diffractometer and copper radiation $(\mathrm{CuK} \alpha=1.541178 \AA$ ). X-ray photoelectron (XPS) spectra were collected using a SPECS spectrometer with a 150MCD-9 detector and using a non monochromatic AlK $\alpha$ $(1486.6 \mathrm{eV}) \mathrm{X}$-Ray source. Spectra were recorded using analyzer pass energy of $30 \mathrm{eV}$, an X-ray power of $50 \mathrm{~W}$ and under an operating pressure of $10^{-9}$ mbar. During data processing of the XPS spectra, BE values were referenced to $\mathrm{C} 1 \mathrm{~s}$ peak $(284.5 \mathrm{eV})$. Spectra treatment has been performed using the CASA software. Atomic force microscopy (AFM) images were recorded by using a Multimode Nanoscope 3A instrument operating in tapping mode and with a Si wafer as the substrate. Samples for high resolution electron microscopy (HR-TEM) were ultrasonically dispersed in Milli-Q water and transferred into carbon coated copper grids. HR-TEM images were recorded by using a JEOL JEM2100F microscope operating at $200 \mathrm{kV}$.

\subsection{Synthesis and characterization of $G O$}

GO has been prepared by following the improved Hummer's synthetic method, and by optimization of a previous reported procedure $[43,44]$. A mixture of concentrated $\mathrm{H}_{2} \mathrm{SO}_{4} / \mathrm{H}_{3} \mathrm{PO}_{4}(360: 40 \mathrm{~mL})$ was added to a mixture of graphite $(3 \mathrm{~g})$ and $\mathrm{KMnO}_{4}(18 \mathrm{~g})$ to produce an exothermic reaction to $35-40^{\circ} \mathrm{C}$. The reaction was then heated to $50^{\circ} \mathrm{C}$ and stirred for $13 \mathrm{~h}$, then cooled to room temperature and poured onto $400 \mathrm{~mL}$ of ice with $30 \% \mathrm{H}_{2} \mathrm{O}_{2}(3 \mathrm{~mL})$. After air cooling, the suspension was filtered and washed first with an aqueous $\mathrm{HCl}(1: 10,37 \%)$ solution, and finally with water until $\mathrm{pH}$ 7. The resulting solid was sus- pended in water $(400 \mathrm{~mL})$ and sonicated for $30 \mathrm{~min}$; then the suspension was centrifuged at $4000 \mathrm{rpm}$ for $4 \mathrm{~h}$ and the solid was removed. The liquid suspension was newly centrifuged at $15000 \mathrm{rpm}$ for $1 \mathrm{~h}$, and the resulting solid was dried at $60^{\circ} \mathrm{C}$ to afford $c a$. $1 \mathrm{~g}$ of a dark brown material identified as GO. This material has been characterized by FT-IR, Raman, XRD, XPS, solid-state ${ }^{13} \mathrm{C}$ MAS-NMR, AFM, HR-TEM, and combustion chemical analyses (C 40.07\%, H 2.19\%, N 0.0\%).

\subsection{Chemical trapping of ${ }^{1} \mathrm{O}_{2}$}

Photo-oxidation reactions were performed under air inside $3 \mathrm{~mL}$ fluorescence quartz cuvettes ( $1 \mathrm{~cm}$ light path) containing aerated aqueous solutions of the singlet oxygen trap ABDA $(3 \mathrm{~mL}, 50 \mu \mathrm{M})$ and $\mathrm{RB}$ $(4 \mu \mathrm{M})$ or hetereogeneous $\mathrm{GO}(0.05 \mathrm{mg} / \mathrm{mL})$ photosensitizers. Prior to irradiation, GO was dispersed in distilled water $(1 \mathrm{mg} / \mathrm{mL})$, sonicated for $60 \mathrm{~min}$, and $150 \mu \mathrm{L}$ of the resulting dispersion was diluted to $3 \mathrm{~mL}$ and sonicated again for $1 \mathrm{~min}$. Irradiations were carried out, with continuous stirring, using a cylindrical reactor (equipped with LED lamps, $400-700 \mathrm{~nm}$ emission output, $15.6 \mathrm{~mW} / \mathrm{cm}^{2}$ ) placed $2 \mathrm{~cm}$ away from the cuvette. The evolution of the photoreactions was monitored over time (maximum $16 \mathrm{~min}$.) by means of fluorescence spectroscopy (decrease of fluorescence emission at $\lambda_{\text {em }}=430 \mathrm{~nm}, \lambda_{\text {exc }}=375 \mathrm{~nm}$ ). The initial points of the kinetic traces were fitted to a pseudo-first order model (ln $\mathrm{C} / \mathrm{C}_{0}=-\mathrm{k}_{\mathrm{obs}} \cdot \mathrm{t}$, where $\mathrm{C}$ is the concentration of ABDA at a certain time $t$ and $C_{0}$ is the initial concentration of ABDA (for low concentrations is can be assumed that fluorescence intensity is proportional to concentration). The same methodology was followed by using fullerene- $\mathrm{C}_{60}$ $(0.05 \mathrm{mg} / \mathrm{mL})$ as photosensitizer and DMA $(3 \mathrm{~mL}, 50 \mu \mathrm{M})$ as a probe in toluene. Control experiments were performed by using ABDA in the absence of the photosensitizer, in the dark or under $\mathrm{N}_{2}$ atmosphere, using $\mathrm{GO}$ as photosensitizer. Quenching experiments were done in the presence of $\mathrm{NaN}_{3}(10 \mathrm{mM})$.

\subsection{Direct singlet oxygen detection}

The singlet oxygen phosphorescence decay traces after the laser pulse were registered at $c a .1275 \mathrm{~nm}$ employing a Peltier-cooled $\left(-62.8^{\circ} \mathrm{C}\right)$ Hamamatsu NIR detector coupled to a computer-controlled grating monochromator. A pulsed Nd:YAG L52137 V LOTIS TII was used at the excitation wavelength of $355 \mathrm{~nm}$. The single pulses were ca. $10 \mathrm{~ns}$ duration, and the energy was lower than $5 \mathrm{~mJ}$ per pulse. The system consisted of a pulsed laser, a 77250 Oriel monochromator coupled to a Hamamatsu NIR detector operating at $650 \mathrm{~V}$, and an oscilloscope connected to the computer. The output signal was transferred from the oscilloscope to the computer. All measurements were made at room temperature, under air atmosphere, and using the chosen solvent (MilliQ water for previously ultrasonically dispersed GO, and toluene for fullerene- $C_{60}$ ) in $10 \times 10 \mathrm{~mm}^{2}$ quartz cells with a capacity of $4 \mathrm{~mL}$. The absorbance of the freshly prepared samples was adjusted to 0.28 for the singlet oxygen measurements at the laser excitation wavelength.

\section{Results and discussion}

GO was synthesized by an optimization of the improved Hummers method $[43,44]$. The characterization of the material was done using spectroscopic, X-ray, morphological, and combustion chemical analyses [13]. The identification of hydroxyl, epoxy and carboxylic groups in the GO structure has been confirmed by infrared, solid-state ${ }^{13} \mathrm{C}$ MAS-NMR and XPS analyses (Fig. 1, A-C) [45,46]. The Raman spectrum of GO (Fig. 1D) shows the characteristic D $\left(1346 \mathrm{~cm}^{-1}\right)$ and $G$ bands $\left(1605 \mathrm{~cm}^{-1}\right)$, where the $\mathrm{G}$ band is associated to the carbon-carbon vibrations of the aromatic rings, and the $\mathrm{D}$ band to the presence of defects and to the grade of disorder introduced by the oxygen functionali- 

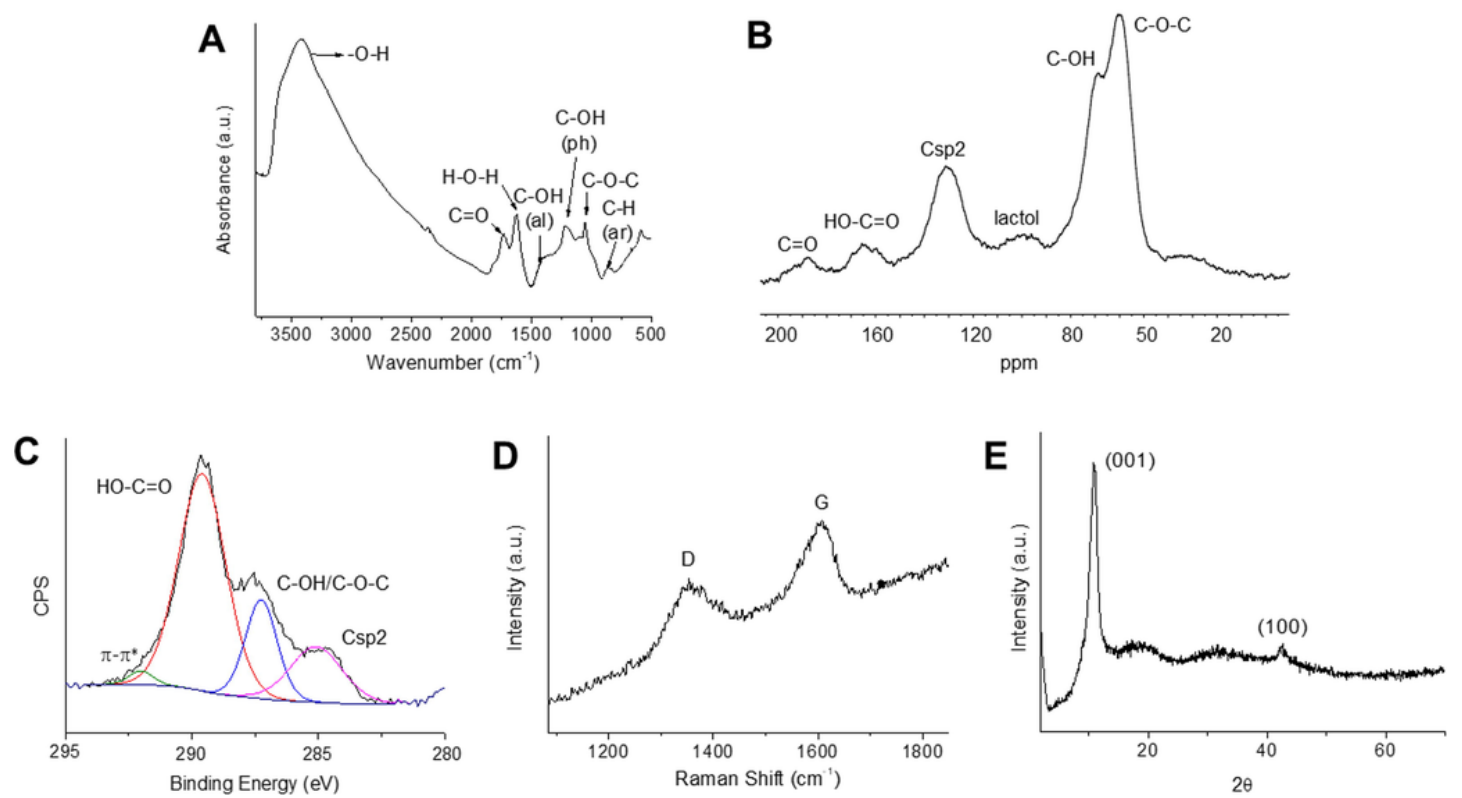

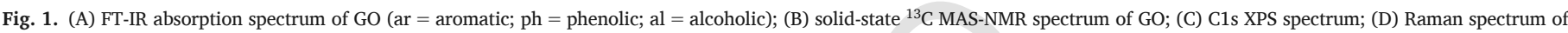
GO measured at $514 \mathrm{~nm}$; (E) XRD pattern of GO.

ties [47-50]. The XRD pattern of GO nanosheets (Fig. 1E) reveals the most prominent $(001)$ diffraction peak centered at $2 \Theta 11.5^{\circ}$, which corresponds to an interlamellar spacing $\left(7.64^{\circ}\right)$ associated to the grade of oxidation of the graphene sheets, and a turbostratic stacking arrangement of the structure [51,52]. The presence of single and 2-4 layers of GO have been confirmed by HR-TEM and AFM techniques (Fig. 2) $[53,54]$.

In order to assess the production of ${ }^{1} \mathrm{O}_{2}$, the probe ABDA (Fig. 3) was used since it is widely employed as a trap for this species in the biomedical realm and can be monitored easily by UV-vis absorption or fluorescence spectroscopies $[55,56]$. The underlying operational principle for ABDA involves the disappearance of its main absorption centred at $375 \mathrm{~nm}$ (and hence its fluorescence emission at $\lambda=430 \mathrm{~nm}$ ) after reaction with ${ }^{1} \mathrm{O}_{2}$ (ABDA $\mathrm{O}_{2}$ endoperoxide depicted in Fig. 3 is formed). In Fig. 3 it is shown a representative series of fluorescence spectra, specifically monitoring the reaction of ABDA with ${ }^{1} \mathrm{O}_{2}$ generated by the well-known photosensitizer Rose Bengal (RB).
An aqueous suspension of $\mathrm{GO}(0.05 \mathrm{mg} / \mathrm{mL})$ was prepared, in the presence of ABDA $(50 \mu \mathrm{M})$, and irradiated with a photo-reactor containing white light emitting diodes (LED 400-700 nm). The fluorescence emission of ABDA was recorded and the intensity plotted against the irradiation time (Fig. 4). The data were fitted to a pseudo-first order model, and $\mathrm{k}_{\mathrm{obs}}$ are compiled in Table 1 . The reaction was repeated in deuterated water since it is reported that the rates of singlet oxygen mediated reactions are enhanced in this medium (about ten-fold) due to the longer lifetime of ${ }^{1} \mathrm{O}_{2}$ as compared to water $(67.9 \mu \mathrm{s} v \mathrm{~s}$ $3.45 \mu$ s in $\mathrm{D}_{2} \mathrm{O}$ and $\mathrm{H}_{2} \mathrm{O}$, respectively) [57]. The isotopic effect can be expressed as the rate of the constants in water and $\mathrm{D}_{2} \mathrm{O}\left(\mathrm{k}_{\mathrm{D}} / \mathrm{k}_{\mathrm{H}}\right)$ resulting a value of $c a$. 3. Finally the use of a specific quencher of singlet oxygen, like $\mathrm{NaN}_{3}$, was assayed [58]. The azide quencher did not cause any relevant decrease in the rate, resulting a value for this effect of $\mathrm{k}_{\mathrm{H}} / \mathrm{k}_{\mathrm{H}}\left(\mathrm{N}_{3}{ }^{-}\right)=1.1$. A well-known photosensitizer like $\mathrm{RB}$ was tested as a control. In this case the isotopic effect was found according to the expected value $\left(\mathrm{k}_{\mathrm{D}} / \mathrm{k}_{\mathrm{H}}\right.$ is $c a$. 7) and more importantly, the azide effect
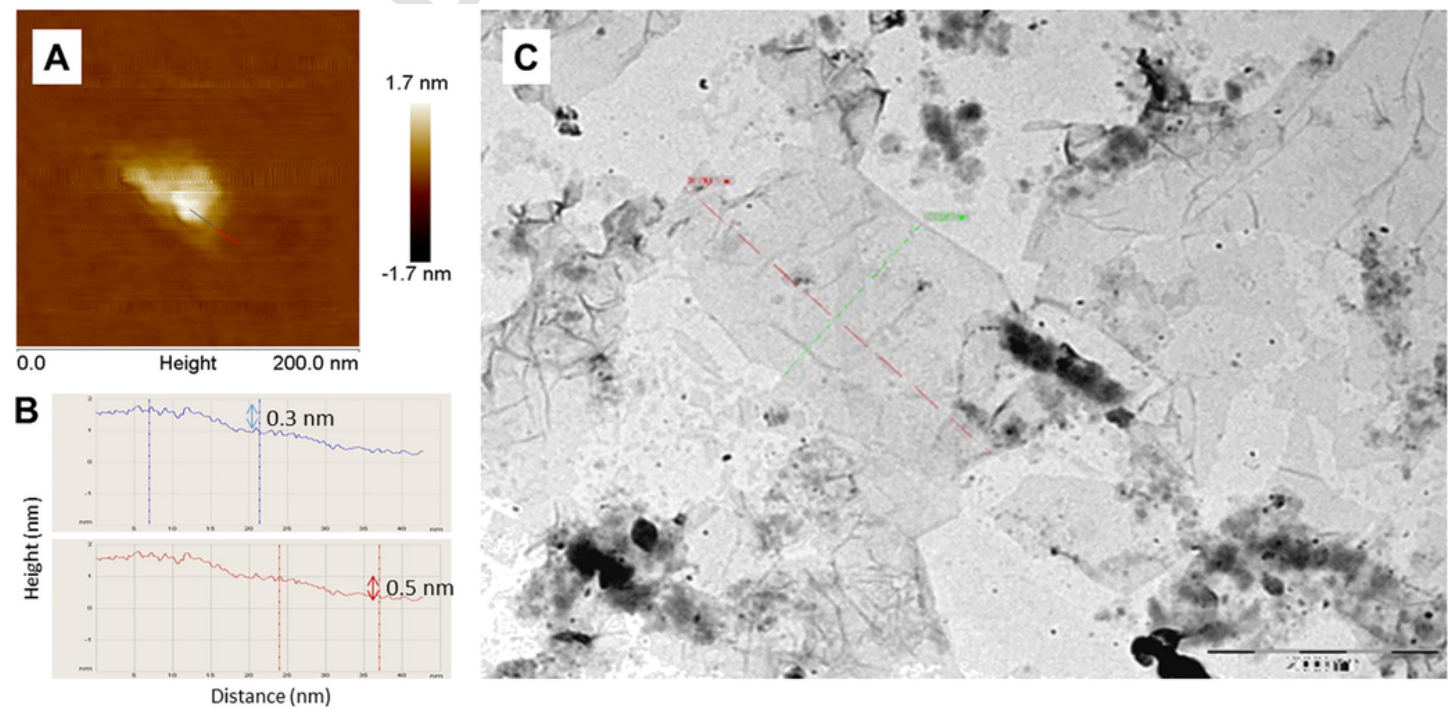

Fig. 2. (A) AFM image of GO; (B) the height profile of the AFM image; (C) HR-TEM image of GO. 
<smiles>O=C1Oc2c3ccccc3c(C(C(=O)O)C(=O)O)c3cccc1c23</smiles><smiles>CC(C)(C)C1(C)CCCCC1</smiles>

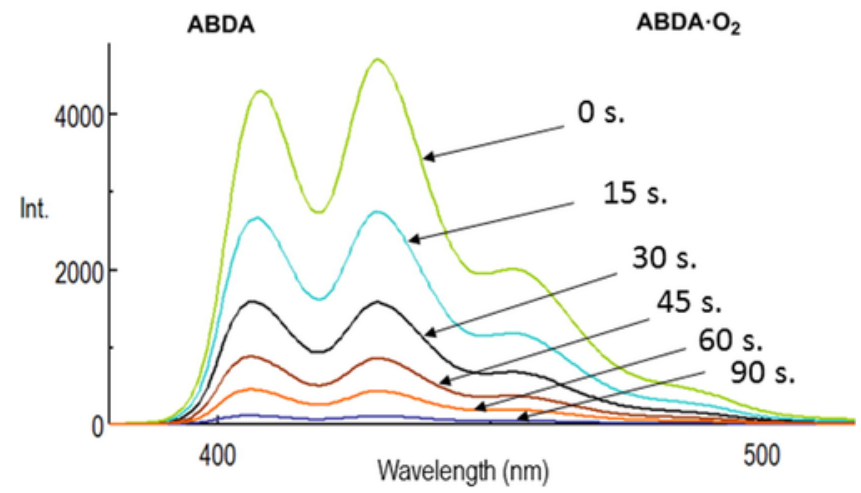

Fig. 3. Representative irradiation of the well-known photosensitizer $\mathrm{RB}$ in $\mathrm{D}_{2} \mathrm{O}$ and monitoring of the generation of ${ }^{1} \mathrm{O}_{2}$ by means of ABDA (see details in entry 14 in Table 1).

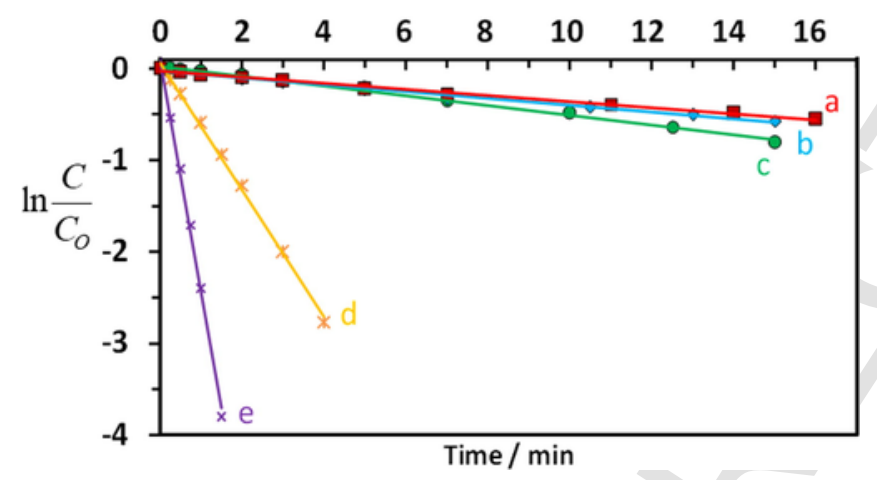

Fig. 4. Selected irradiations conducted in this study, using the quenching of ABDA fluorescence as spectroscopic test: a) GO in $\mathrm{D}_{2} \mathrm{O}$ with $\mathrm{N}_{3}{ }^{-}$as quencher; b) $\mathrm{GO}$ in $\mathrm{D}_{2} \mathrm{O}$; c) $\mathrm{RB}$ in $\mathrm{D}_{2} \mathrm{O}$ with $\mathrm{N}_{3}{ }^{-}$as quencher; d) Fullerene- $\mathrm{C}_{60}$ in toluene; e) RB in $\mathrm{D}_{2} \mathrm{O}$. All heterogeneous photooxidations were performed at $0.05 \mathrm{mg} \mathrm{GO} / \mathrm{ml}$; $[\mathrm{RB}]=4 \mu \mathrm{M}$; $[\mathrm{ABDA}]=50 \mu \mathrm{M}$; $\left[\mathrm{N}_{3}^{-}\right]=10 \mathrm{mM}$. was as pronounced as described in the literature $\left(\mathrm{k}_{\mathrm{D}} / \mathrm{k}_{\mathrm{D}}\left(\mathrm{N}_{3}{ }^{-}\right)=47.6\right)$. See all the kinetic traces in Fig. 4 and a compilation of the values in Table 1. Overall, considering the weak isotopic effect and absence of quenching by azide, in the case of $\mathrm{GO}$, it must be concluded that the drop in the emission of ABDA would not be attributable to ${ }^{1} \mathrm{O}_{2}$ but to another side reaction.

Although it was not possible to set samples with comparable absorptions due to the dispersion of GO, it seems clear, although only qualitatively, that the kinetics of $\mathrm{RB}$ is notably faster than the rate measured for GO. As a matter of fact, $R B$ depletes the emission of ABDA in seconds (Fig. 3), whereas the photoirradiation of GO leads to minor detectable changes in ABDA fluorescence only after minutes. This supports the view that the amount of generated ${ }^{1} \mathrm{O}_{2}$ by GO must be minimal. Just for qualitative assessment another well-known photosensitizer, fullerene- $\mathrm{C}_{60}$, was used to certify that GO generates very low amounts of ${ }^{1} \mathrm{O}_{2}$. The purpose of this assay was to use an excellent photosensitizer $\left(\phi_{\Delta}=0.96\right)$ with a comparable absorption to GO [59]. Hence, a sample of $0.05 \mathrm{mg} / \mathrm{mL}$ of fullerene- $\mathrm{C}_{60}$ was irradiated in toluene, since this photosensitizer generates efficiently ${ }^{1} \mathrm{O}_{2}$ in organic apolar medium (but not in water). In this case another anthracene derivative was employed (dimethylanthracene, DMA) since ABDA is not soluble in toluene. The measured reaction rate was $0.6920 \mathrm{~min}^{-1}$. Considering that the lifetime of singlet oxygen in toluene $(30.3 \mu \mathrm{s})$ is about half of the value in $\mathrm{D}_{2} \mathrm{O}$ [57], this result supports the idea of minimal amount of ${ }^{1} \mathrm{O}_{2}$ generated by $\mathrm{GO}$ upon irradiation.

A question that can be raised is whether the slight decrease of the ABDA fluorescence could be attributed to other species different from ${ }^{1} \mathrm{O}_{2}$. It is described that anthracene and its derivatives (An) are very prone to oxidation leading to the corresponding radical cation $\left(\mathrm{An}^{+}{ }^{\bullet}\right.$ ). This species react with superoxide to give an adduct $\left(\mathrm{AnO}_{2}\right)$ identical to the one obtained by reaction with singlet oxygen. This reaction has been described many times for anthracene and electron transfer photosensitizers [60]. As a matter of fact, the specificity of anthracenic probes for the detection of ${ }^{1} \mathrm{O}_{2}$ has been studied in detail recently: the genetically encodable fluorescent tag miniSOG has been reported to produce ${ }^{1} \mathrm{O}_{2}$ with a notable quantum yield (0.47) using the probe ADPA [61]. However, Nonell and Flors have measured a significantly smaller value (0.03) [62]. This discrepancy was attributed to the ability of miniSOG to photooxidize the probe and hence lead to reaction with superoxide. Hence, ADPA would be actually measuring both ROS produced by type I (electron transfer) and type II (energy transfer) mechanisms. In another example, the endoperoxide of DMA was formed upon irradiation of alkyloxo(methoxo) tetraphenylporphyrinato-antimony via photoinduced electron transfer mechanism involving $\mathrm{DMA}^{+}$and $\mathrm{O}_{2}^{-{ }^{-}}$exclusively [63]. Accordingly, the mechanism involv-

Table 1

Kinetic determinations using ABDA for different irradiations.

\begin{tabular}{|c|c|c|c|c|c|c|c|}
\hline Entry & Material & Probe & Solvent & Atmosphere & Quencher & Light source & $\mathrm{k}_{\mathrm{obs}}\left(\mathrm{min}^{-1}\right)$ \\
\hline 1 & GO (run 1) & ABDA & $\mathrm{H}_{2} \mathrm{O}$ & Air & - & LED & 0.0110 \\
\hline 2 & GO (run 2) & ABDA & $\mathrm{H}_{2} \mathrm{O}$ & Air & - & LED & 0.0118 \\
\hline 3 & GO (run 3) & ABDA & $\mathrm{H}_{2} \mathrm{O}$ & Air & - & LED & 0.0103 \\
\hline 4 & GO (run 1) & ABDA & $\mathrm{D}_{2} \mathrm{O}$ & Air & - & LED & 0.0328 \\
\hline 5 & GO (run 2) & ABDA & $\mathrm{D}_{2} \mathrm{O}$ & Air & - & LED & 0.0373 \\
\hline 6 & GO (run 3) & ABDA & $\mathrm{D}_{2} \mathrm{O}$ & Air & - & LED & 0.0368 \\
\hline 7 & GO (run 1 ) & ABDA & $\mathrm{D}_{2} \mathrm{O}$ & Air & $\mathrm{N}_{3}^{-}$ & LED & 0.0335 \\
\hline 8 & GO (run 2) & ABDA & $\mathrm{D}_{2} \mathrm{O}$ & Air & $\mathrm{N}_{3}^{-}$ & LED & 0.0331 \\
\hline 9 & GO (run 3) & ABDA & $\mathrm{D}_{2} \mathrm{O}$ & Air & $\mathrm{N}_{3}^{-}$ & LED & 0.0342 \\
\hline 10 & $-($ control $)$ & ABDA & $\mathrm{H}_{2} \mathrm{O}$ & Air & - & LED & $<0.001$ \\
\hline 11 & $\mathrm{GO}$ & ABDA & $\mathrm{H}_{2} \mathrm{O}$ & $\mathrm{N}_{2}$ (control) & - & LED & $<0.001$ \\
\hline 12 & GO & ABDA & $\mathrm{H}_{2} \mathrm{O}$ & Air & - & - (control) & $<0.001$ \\
\hline 13 & $\mathrm{RB}$ & ABDA & $\mathrm{H}_{2} \mathrm{O}$ & Air & - & LED & 0.3834 \\
\hline 14 & $\mathrm{RB}$ & ABDA & $\mathrm{D}_{2} \mathrm{O}$ & Air & - & LED & 2.576 \\
\hline 15 & $\mathrm{RB}$ & ABDA & $\mathrm{D}_{2} \mathrm{O}$ & Air & $\mathrm{N}_{3}^{-}$ & LED & 0.0533 \\
\hline 16 & Fullerene- $\mathrm{C}_{60}$ & DMA & toluene & Air & - & LED & 0.6920 \\
\hline
\end{tabular}


ing $\mathrm{O}_{2}{ }^{-}$described in Eqs. (1)-(4) can be proposed to account for the minimal bleaching of ABDA upon irradiation of GO. In this case, apart from ${ }^{1} \mathrm{O}_{2}$, the superoxide anion would be involved in the reaction with ABDA. Unfortunately the slopes of the kinetics recorded in this study are too close to the control irradiations to allow any conclusion on this regard. What it can be affirmed, however, is that ${ }^{1} \mathrm{O}_{2}$ production by irradiated GO (under visible light with soft irradiation conditions and short times) is close to the detection capability of the technique, and hence disregard any reasonable toxicity associated to the production of this specific ROS by our material.

$\mathrm{GO}+\mathrm{h} \rightarrow \mathrm{GO} *$

$\mathrm{GO} *+\mathrm{ABDA} \rightarrow \mathrm{GO}^{-}+\mathrm{ABDA}^{+}$

$\mathrm{GO}^{-\cdot}+\mathrm{O}_{2} \rightarrow \mathrm{O}_{2}^{-\cdot}+\mathrm{GO}$

$\mathrm{ABDA}^{+\cdot}+\mathrm{O}_{2}^{-\cdot} \rightarrow \mathrm{ABDA} / \mathrm{O}_{2}$

It is not ruled out that ageing of the GO samples would led to the formation of byproducts similar to rGO and low molecular-weight species, as recently demonstrated by other groups $[37,38,64]$. If this is the case, the origin of $\mathrm{O}_{2}{ }^{-}$ would be this phototransformed fraction of the sample since it has been demonstrated the reducing capacity of rGO. However this possibility is very unlikely in our case since photoreduction of GO to rGO has been described using high energetic UV light during several hours, whereas we are using a source of visible light and very short irradiation periods (minutes), precisely to avoid photoageing of our GO. The ageing of GO upon irradiation is a matter of debate that falls out of the scope of this research, which is focused on the use of sensitive spectroscopic probes to study GO, as a complementary tool to FFA and chromatography.

Finally, a direct measurement of the phosphorescence of ${ }^{1} \mathrm{O}_{2}$ at $c a$. $1275 \mathrm{~nm}$ was also attempted [57], since this is an irrefutable probe of the existence of this ROS. Hence, GO dispersed in water and irradiated at $355 \mathrm{~nm}$ yielded only a noisy signal (red line, Fig. 5), in contrast with the strong intensity showed by irradiated fullerene- $\mathrm{C}_{60}$ in toluene

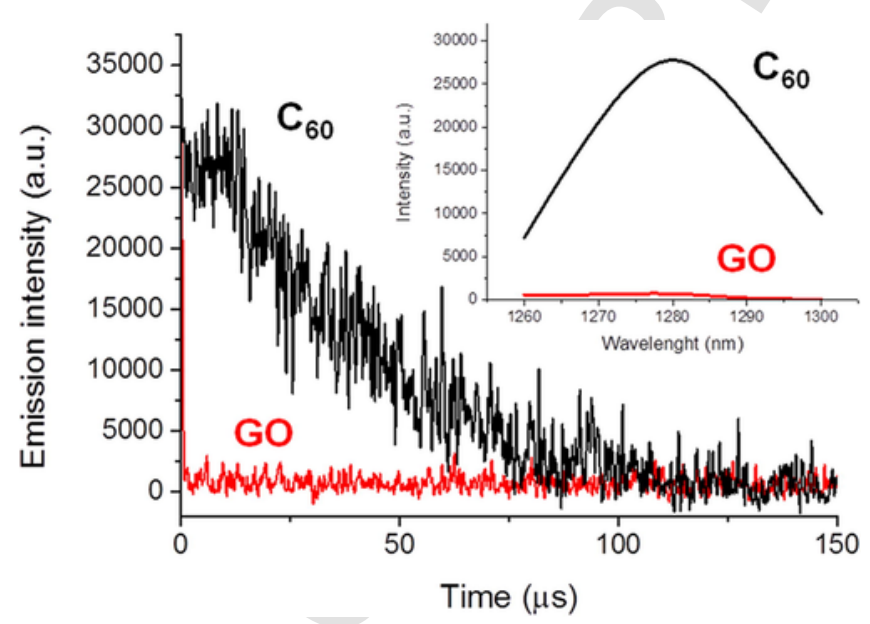

Fig. 5. Time profiles of the ${ }^{1} \mathrm{O}_{2}$ phosphorescence signal produced by fullerene- $\mathrm{C}_{60}$ (black line) and GO (red line) in water and toluene, respectively. Inset: singlet oxygen emission spectra for fullerene- $\mathrm{C}_{60}$ and $\mathrm{GO}$ acquired at $c a .10 \mu \mathrm{s}$ after the laser pulse. The samples were adjusted to the same absorbance at the excitation wavelength $(355 \mathrm{~nm})$ and the phosphorescence of ${ }^{1} \mathrm{O}_{2}$ was recorded at $c a .1275 \mathrm{~nm}$. (black line, Fig. 5) used as a positive control. This experiment also confirms the negligible generation of ${ }^{1} \mathrm{O}_{2}$ when our GO is irradiated, at least up to the limit of detection of the employed methodologies.

\section{Conclusions}

We have found that generation of singlet oxygen upon short periods of visible light irradiation of samples of freshly prepared GO is almost negligible, using a high sensitivity spectroscopic fluorescent probe like ABDA. Exact quantification of this species remained elusive due to the dispersion of GO in water (light scattering), however there is enough qualitative evidence to suggest that the irradiation of GO with visible light during short periods of time gives rise to negligible amounts of this ROS. These results confirm recent measurements reported by other groups using FFA and chromatographic analyses as tools. We hope, firstly, that this study will contribute to answer some questions regarding the potential toxicity of nanomaterials derived from graphene and, secondly, that it will add ABDA, or other fluorescence probes, along with direct detection via phosphorescence emission, to the toolbox that environmental scientist use in their researches.

\section{Declaration of Competing Interest}

None.

\section{Acknowledgements}

Ministerio de Economía y Competitividad of Spain (grant CTQ2015-71004-R) and Universitat Jaume I (grant P1.1B2015-76) are thanked for their financial support. C.F-L. thanks the Ministerio de Economía y Competitividad of Spain for a FPI fellowship. Technical support from SCIC of University Jaume I is acknowledged. The Instituto de Tecnología Química (ITQ) thanks the support of the Severo Ochoa Program (SEV-2016-0683), and Consejo Superior de Investigaciones Científicas (I-Link1063). We would like to thank Dr. Francisco Bosca for his technical assistance with the singlet oxygen emission measurements at the ITQ.

\section{Appendix A. Supplementary data}

Supplementary data to this article can be found online at https:// doi.org/10.1016/j.matlet.2019.05.001.

\section{References}

[1] Q. Quan, X. Lin, N. Zhang, Y.-J. Xu, Graphene and its derivatives as versatile templates for materials synthesis and functional applications, Nanoscale 9 (2017) 2398-2416, https://doi.org/10.1039/C6NR09439B.

[2] V. Georgakilas, J.A. Perman, J. Tucek, R. Zboril, Broad family of carbon nanoallotropes: classification, chemistry, and applications of fullerenes, carbon dots, nanotubes, graphene, nanodiamonds, and combined superstructures, Chem. Rev. 115 (2015) 4744-4822, https://doi.org/10.1021/cr500304f.

[3] G. Hong, S. Diao, A.L. Antaris, H. Dai, Carbon nanomaterials for biological imaging and nanomedicinal therapy, Chem. Rev. 115 (2015) 10816-10906, https://doi. org/10.1021/acs.chemrev.5b00008.

[4] Z. Liu, X.-J. Liang, Nano-carbons as theranostics, Theranostics 2 (2012) 235-237 http://www.thno.org/v02p0235.htm.

[5] K.P. Loh, Q. Bao, G. Eda, M. Chhowalla, Graphene oxide as a chemically tunable platform for optical applications, Nat. Chem. 2 (2010) 1015-1024, https://doi.org/ 10.1038/nchem.907.

[6] L. Kong, W. Chen, Carbon nanotube and graphene-based bioinspired electrochemical actuators, Adv. Mater. 26 (2014) 1025-1043, https://doi.org/10.1002/adma. 201303432.

[7] K. Rana, J. Singh, J.-H. Ahn, A graphene-based transparent electrode for use in flexible optoelectronic devices, J. Mater. Chem. C 2 (2014) 2646-2656, https:// doi.org/10.1039/C3TC32264E.

[8] X. Li, Y. Zhu, W. Cai, M. Borysiak, B. Han, D. Chen, R.D. Piner, L. Colombo, R.S. Ruoff, Transfer of large-area graphene films for high-performance transparent conductive electrodes, Nano Lett. 9 (2009) 4359-4363, https://doi.org/10.1021/ nl902623y. 
[9] R.K. Koninti, A. Sengupta, K. Gavvala, N. Ballav, P. Hazra, Loading of an anti-cancer drug onto graphene oxide and subsequent release to DNA/RNA: a direct optical detection, Nanoscale 6 (2014) 2937-2944, https://doi.org/10.1039/C3NR06081K.

[10] V. Georgakilas, J.N. Tiwari, K.C. Kemp, J.A. Perman, A.B. Bourlinos, K.S. Kim, R. Zboril, Noncovalent functionalization of graphene and graphene oxide for energy materials, biosensing, catalytic, and biomedical applications, Chem. Rev. 116 (2016) 5464-5519, https://doi.org/10.1021/acs.chemrev.5b00620.

[11] D. Rodriguez-San-Miguel, P. Amo-Ochoa, F. Zamora, MasterChem: cooking 2D-polymers, Chem. Commun. 52 (2016) 4113-4127, https://doi.org/10.1039/ C5CC10283A.

[12] D.R. Dreyer, A.D. Todd, C.W. Bielawski, Harnessing the chemistry of graphene oxide, Chem. Soc. Rev. 43 (2014) 5288-5301, https://doi.org/10.1039/ C4CS00060A.

[13] D.R. Dreyer, S. Park, C.W. Bielawski, R.S. Ruoff, The chemistry of graphene oxide, Chem. Soc. Rev. 39 (2010) 228-240, https://doi.org/10.1039/B917103G.

[14] D.R. Dreyer, R.S. Ruoff, C.W. Bielawski, From conception to realization: an historial account of graphene and some perspectives for its future, Angew. Chem. Int. Ed. 49 (2010) 9336-9344, https://doi.org/10.1002/anie.201003024.

[15] K. Ghosal, K. Sarkar, Biomedical applications of graphene nanomaterials and beyond, ACS Biomater. Sci. Eng. 4 (2018) 2653-2703, https://doi.org/10.1021/ acsbiomaterials.8b00376.

[16] V.C. Sanchez, A. Jachak, R.H. Hurt, A.B. Kane, Biological interactions of graphene-family nanomaterials: an interdisciplinary review, Chem. Res. Toxicol. 25 (2012) 15-34, https://doi.org/10.1021/tx200339h.

[17] A. Bianco, Graphene: safe or toxic? The two faces of the medal, Angew. Chem. Int. Ed. 52 (2013) 4986-4997, https://doi.org/10.1002/anie.201209099.

[18] A.B. Seabra, A.J. Paula, R. de Lima, O.L. Alves, N. Durán, Nanotoxicity of graphene and graphene oxide, Chem. Res. Toxicol. 27 (2014) 159-168, https://doi.org/10. 1021/tx400385x.

[19] A.D. Maynard, R.J. Aitken, 'Safe handling of nanotechnology' ten years on, Nat. Nano 11 (2016) 998-1000, https://doi.org/10.1038/nnano.2016.270.

[20] A.D. Maynard, R.J. Aitken, T. Butz, V. Colvin, K. Donaldson, G. Oberdorster, M.A. Philbert, J. Ryan, A. Seaton, V. Stone, S.S. Tinkle, L. Tran, N.J. Walker, D.B. Warheit, Safe handling of nanotechnology, Nature 444 (2006) 267-269, https:// doi.org/10.1038/444267a.

[21] L. Ou, B. Song, H. Liang, J. Liu, X. Feng, B. Deng, T. Sun, L. Shao, Toxicity of graphene-family nanoparticles: a general review of the origins and mechanisms, Part. Fibre Toxicol. 13 (2016) 57 http://www.ncbi.nlm.nih.gov/pmc/articles/ PMC5088662/.

[22] Y. Gao, Y. Li, L. Zhang, H. Huang, J. Hu, S.M. Shah, X. Su, Adsorption and remova of tetracycline antibiotics from aqueous solution by graphene oxide, J. Colloid Interface Sci. 368 (2012) 540-546 http://www.sciencedirect.com/science/article/ pii/S0021979711013919.

[23] D.G. Goodwin, A.S. Adeleye, L. Sung, K.T. Ho, R.M. Burgess, E.J. Petersen, Detection and quantification of graphene-family nanomaterials in the environment, Env iron. Sci. Technol. 52 (2018) 4491-4513, https://doi.org/10.1021/acs.est. $7 \mathrm{~b} 04938$.

[24] B. Avant, D. Bouchard, X. Chang, H.-S. Hsieh, B. Acrey, Y. Han, J. Spear, R. Zepp, C.D. Knightes, Environmental fate of multiwalled carbon nanotubes and graphene oxide across different aquatic ecosystems, NanoImpact 13 (2019) 1-12 http:// www.sciencedirect.com/science/article/pii/S2452074818301575.

[25] B. Khan, A.S. Adeleye, R.M. Burgess, R. Smolowitz, S.M. Russo, K.T. Ho, A 72-h ex posure study with eastern oysters (Crassostrea virginica) and the nanomaterial graphene oxide, Environ. Toxicol. Chem. 38 (2019) 820-830 https://setac. onlinelibrary.wiley.com/doi/abs/10.1002/etc. 4367.

[26] J.-L. Li, B. Tang, B. Yuan, L. Sun, X.-G. Wang, A review of optical imaging and therapy using nanosized graphene and graphene oxide, Biomaterials 34 (2013) 9519-9534 http://www.sciencedirect.com/science/article/pii/ S0142961213010296.

[27] P. Kalluru, R. Vankayala, C.-S. Chiang, K.C. Hwang, Nano-graphene oxide-mediated In vivo fluorescence imaging and bimodal photodynamic and phototherma destruction of tumors, Biomaterials 95 (2016) 1-10 http://www.sciencedirect. com/science/article/pii/S014296121630103X.

[28] D.W. Hwang, H.Y. Kim, F. Li, J.Y. Park, D. Kim, J.H. Park, H.S. Han, J.W. Byun, Y.-S. Lee, J.M. Jeong, K. Char, D.S. Lee, In vivo visualization of endogenous miR-21 using hyaluronic acid-coated graphene oxide for targeted cancer therapy, Biomaterials 121 (2017) 144-154 http://www.sciencedirect.com/science/article/ pii/S0142961216307475.

[29] Q. Bao, D. Zhang, P. Qi, Synthesis and characterization of silver nanoparticle and graphene oxide nanosheet composites as a bactericidal agent for water disinfection, J. Colloid Interface Sci. 360 (2011) 463-470 http://www.sciencedirect.com/ science/article/pii/S002197971100587X.

[30] W.-C. Hou, C.T. Jafvert, Photochemistry of aqueous C60 clusters: evidence of 102 formation and its role in mediating $\mathrm{C} 60$ phototransformation, Environ. Sci. Technol. 43 (2009) 5257-5262, https://doi.org/10.1021/es900624s.

[31] C.-Y. Chen, C.T. Jafvert, Photoreactivity of carboxylated single-walled carbon nanotubes in sunlight: reactive oxygen species production in water, Environ. Sci. Tech nol. 44 (2010) 6674-6679, https://doi.org/10.1021/es101073p.

[32] C.-Y. Chen, R.G. Zepp, Probing photosensitization by functionalized carbon nanotubes, Environ. Sci. Technol. 49 (2015) 13835-13843, https://doi.org/10.1021/ acs.est.5b01041.

[33] J. Ge, M. Lan, B. Zhou, W. Liu, L. Guo, H. Wang, Q. Jia, G. Niu, X. Huang, H. Zhou, X. Meng, P. Wang, C.-S. Lee, W. Zhang, X. Han, A graphene quantum dot photody- namic therapy agent with high singlet oxygen generation, Nat. Commun. 5 (2014) 4596, https://doi.org/10.1038/ncomms5596.

[34] K. Krishnamoorthy, R. Mohan, S.-J. Kim, Graphene oxide as a photocatalytic material, Appl. Phys. Lett. 98 (2011), 244101 http://aip.scitation.org/doi/abs/10. 1063/1.3599453.

[35] Y. Zhao, C.T. Jafvert, Environmental photochemistry of single layered graphene oxide in water, Environ. Sci. Nano 2 (2015) 136-142, https://doi.org/10.1039/ C4EN00209A.

[36] T. Dutta, R. Sarkar, B. Pakhira, S. Ghosh, R. Sarkar, A. Barui, S. Sarkar, ROS generation by reduced graphene oxide ( $\mathrm{rGO}$ ) induced by visible light showing antibacterial activity: comparison with graphene oxide (GO), RSC Adv. 5 (2015) 80192-80195, https://doi.org/10.1039/C5RA14061G.

[37] A.S. Adeleye, X. Wang, F. Wang, R. Hao, W. Song, Y. Li, Photoreactivity of graphene oxide in aqueous system: Reactive oxygen species formation and bisphenol A degradation, Chemosphere 195 (2018) 344-350 http://www.sciencedirect. com/science/article/pii/S0045653517320659.

[38] T. Du, A.S. Adeleye, T. Zhang, C. Jiang, M. Zhang, H. Wang, Y. Li, A.A. Keller, W. Chen, Influence of light wavelength on the photoactivity, physicochemical transformation, and fate of graphene oxide in aqueous media, Environ. Sci. Nano 5 (2018) 2590-2603, https://doi.org/10.1039/C8EN00593A.

[39] E. Appiani, R. Ossola, D.E. Latch, P.R. Erickson, K. McNeill, Aqueous singlet oxygen reaction kinetics of furfuryl alcohol: effect of temperature, $\mathrm{pH}$, and salt content, Environ. Sci. Process. Impacts 19 (2017) 507-516, https://doi.org/10.1039/ C6EM00646A.

[40] M. Feliz, M. Puche, P. Atienzar, P. Concepción, S. Cordier, Y. Molard, In situ generation of active molybdenum octahedral clusters for photocatalytic hydrogen production from water, ChemSusChem 9 (2016) 1963-1971, https://doi.org/10. 1002/cssc.201600381.

[41] M. Garcia-Diaz, Y.-Y. Huang, M.R. Hamblin, Use of fluorescent probes for ROS to tease apart Type I and Type II photochemical pathways in photodynamic therapy, Methods 109 (2016) 158-166 http://www.sciencedirect.com/science/article/pii/ S1046202316302006.

[42] R. Bresolí-Obach, J. Nos, M. Mora, M.L. Sagristà, R. Ruiz-González, S. Nonell, Anthracene-based fluorescent nanoprobes for singlet oxygen detection in biological media, Methods 109 (2016) 64-72 http://www.sciencedirect.com/science/article/ pii/S1046202316301712.

[43] D.C. Marcano, D.V. Kosynkin, J.M. Berlin, A. Sinitskii, Z. Sun, A. Slesarev, L.B. Alemany, W. Lu, J.M. Tour, Improved synthesis of graphene oxide, ACS Nano 4 (2010) 4806-4814, https://doi.org/10.1021/nn1006368.

[44] M. Latorre-Sánchez, C. Lavorato, M. Puche, V. Fornés, R. Molinari, H. Garcia, Visible-light photocatalytic hydrogen generation by using dye-sensitized graphene oxide as a photocatalyst, Chem. Eur. J. 18 (2012) 16774-16783, https://doi.org/10. 1002/chem.201202372.

[45] W. Gao, L.B. Alemany, L. Ci, P.M. Ajayan, New insights into the structure and reduction of graphite oxide, Nat. Chem. 1 (2009) 403, https://doi.org/10.1038/ nchem.281.

[46] J.M. Munuera, J.I. Paredes, M. Enterría, A. Pagán, S. Villar-Rodil, M.F.R. Pereira, J.I. Martins, J.L. Figueiredo, J.L. Cenis, A. Martínez-Alonso, J.M.D. Tascón, Electrochemical exfoliation of graphite in aqueous sodium halide electrolytes toward low oxygen content graphene for energy and environmental applications, ACS Appl. Mater. Interfaces 9 (2017) 24085-24099, https://doi.org/10.1021/acsami. $7 \mathrm{~b} 04802$.

[47] A.C. Ferrari, D.M. Basko, Raman spectroscopy as a versatile tool for studying the properties of graphene, Nat. Nanotechnol. 8 (2013) 235, https://doi.org/10.1038/ nnano.2013.46.

[48] L.G. Cançado, A. Jorio, E.H.M. Ferreira, F. Stavale, C.A. Achete, R.B. Capaz, M.V.O. Moutinho, A. Lombardo, T.S. Kulmala, A.C. Ferrari, Quantifying defects in graphene via Raman spectroscopy at different excitation energies, Nano Lett. 11 (2011) 3190-3196, https://doi.org/10.1021/nl201432g.

[49] Y. Hernandez, V. Nicolosi, M. Lotya, F.M. Blighe, Z. Sun, S. De, I.T. McGovern, B. Holland, M. Byrne, Y.K. Gun'Ko, J.J. Boland, P. Niraj, G. Duesberg, S. Krishnamurthy, R. Goodhue, J. Hutchison, V. Scardaci, A.C. Ferrari, J.N. Coleman, High-yield production of graphene by liquid-phase exfoliation of graphite, Nat. Nanotechnol. 3 (2008) 563, https://doi.org/10.1038/nnano.2008.215.

[50] M.S. Dresselhaus, G. Dresselhaus, M. Hofmann, Raman spectroscopy as a probe of graphene and carbon nanotubes, Philos. Trans. A Math. Phys. Eng. Sci. 366 (2008) 231-236 http://rsta.royalsocietypublishing.org/content/roypta/366/1863/231. full.pdf.

[51] H. Bi, K. Yin, X. Xie, J. Ji, S. Wan, L. Sun, M. Terrones, M.S. Dresselhaus, Ultrahigh humidity sensitivity of graphene oxide, Sci. Rep. 3 (2013) 2714, https://doi.org/ 10.1038/srep02714.

[52] M.A. Pimenta, G. Dresselhaus, M.S. Dresselhaus, L.G. Cançado, A. Jorio, R. Saito, Studying disorder in graphite-based systems by Raman spectroscopy, Phys. Chem. Chem. Phys. 9 (2007) 1276-1290, https://doi.org/10.1039/B613962K.

[53] S. Bonnamy, A. Oberlin, Chapter 4 - Transmission Electron Microscopy, in: M. Inagaki, F. Kang (Eds.), Materials Science and Engineering of Carbon, Butterworth-Heinemann, 2016, pp. 45-70.

[54] J.I. Paredes, S. Villar-Rodil, A. Martínez-Alonso, J.M.D. Tascón, Graphene oxide dispersions in organic solvents, Langmuir 24 (2008) 10560-10564, https://doi. org/10.1021/la801744a.

[55] X. Shen, L. Li, H. Wu, S.Q. Yao, Q.-H. Xu, Photosensitizer-doped conjugated polymer nanoparticles for simultaneous two-photon imaging and two-photon photodynamic therapy in living cells, Nanoscale 3 (2011) 5140-5146, https://doi.org/10. 1039/C1NR11104C. 
[56] Y. Yuan, C.-J. Zhang, S. Xu, B. Liu, A self-reporting AIE probe with a built-in singlet oxygen sensor for targeted photodynamic ablation of cancer cells, Chem. Sci. 7 (2016) 1862-1866, https://doi.org/10.1039/C5SC03583J.

[57] M. Bregnhoj, M. Westberg, F. Jensen, P.R. Ogilby, Solvent-dependent singlet oxygen lifetimes: temperature effects implicate tunneling and charge-transfer interactions, Phys. Chem. Chem. Phys. 18 (2016) 22946-22961, https://doi.org/10.1039/ C6CP01635A.

[58] M.Y. Li, C.S. Cline, E.B. Koker, H.H. Carmichael, C.F. Chignell, P. Bilski, Quenching of singlet molecular oxygen (102) by azide anion in solvent mixtures, Photochem. Photobiol. 74 (2001) 760-764, https://doi.org/10.1562/0031-8655(2001) 0740760QOSMOO2.0.CO2.

[59] J.W. Arbogast, A.P. Darmanyan, C.S. Foote, F.N. Diederich, R.L. Whetten, Y. Rubin, M.M. Alvarez, S.J. Anz, Photophysical properties of sixty atom carbon molecule (C60), J. Phys. Chem. 95 (1991) 11-12, https://doi.org/10.1021/ j100154a006.

[60] H. Kotani, K. Ohkubo, S. Fukuzumi, Photocatalytic oxygenation of anthracenes and olefins with dioxygen via selective radical coupling using 9-mesityl-10-methylacri- dinium ion as an effective electron-transfer photocatalyst, J. Am. Chem. Soc. 126 (2004) 15999-16006, https://doi.org/10.1021/ja048353b.

[61] X. Shu, V. Lev-Ram, T.J. Deerinck, Y. Qi, E.B. Ramko, M.W. Davidson, Y. Jin, M.H. Ellisman, R.Y. Tsien, A genetically encoded tag for correlated light and electron microscopy of intact cells, tissues, and organisms, PLoS Biol. 9 (2011), e1001041 http://journals.plos.org/plosbiology/article?id=10.1371/journal.pbio.1001041.

[62] R. Ruiz-González, A.L. Cortajarena, S.H. Mejias, M. Agut, S. Nonell, C. Flors, Singlet oxygen generation by the genetically encoded tag miniSOG, J. Am. Chem. Soc. 135 (2013) 9564-9567, https://doi.org/10.1021/ja4020524.

[63] J. Matsumoto, T. Beppu, T. Shiragami, M. Yasuda, Mechanistic analysis of the fluorescence quenching of dodecyloxo(methoxo)tetraphenylporphyrinatoantimony by 9,10-dimethylanthracene in an artificial membrane constructed by a phospholipid liposome, J. Photochem. Photobiol. A Chem. 249 (2012) 47-52 http://www. sciencedirect.com/science/article/pii/S1010603012004522.

[64] W.-C. Hou, I. Chowdhury, D.G. Goodwin, W.M. Henderson, D.H. Fairbrother, D. Bouchard, R.G. Zepp, Photochemical transformation of graphene oxide in sunlight, Environ. Sci. Technol. 49 (2015) 3435-3443, https://doi.org/10.1021/es5047155. 